\title{
Complex Mechanism of Phenol Extraction of Coal Gasification Wastewater
}

\author{
Song Du ${ }^{1,2}$, Jikun Wang ${ }^{2}$, Wenbiao Jin ${ }^{1 *}$, Weimin $W_{u^{3}}$ \\ ${ }^{1}$ Harbin Institute of Technology, Shenzhen Graduate School, Shenzhen Engineering Laboratory \\ of Microalgal Bioenergy, Shenzhen, China \\ ${ }^{2}$ Beijing Research Institute of Coal Chemical, China Coal Research Institute, Beijing, China \\ ${ }^{3}$ Department of Civil amd Environmental Engineering, Stanford University, Stanford, California, USA
}

Received: 5 January 2018

Accepted: 20 March 2018

\begin{abstract}
In this study, tri-butyl-phosphate (TBP)-kerosene is used as the extraction solvent to remove phenols from coal gasification wastewater, and the complex mechanism of the extraction is investigated. An effect experiment is conducted to determine the complex structures, the enthalpy change of reaction, and the effect of extraction solvent concentration and temperature on the distribution coefficient. To predict the extraction effect before the experiment, the distribution coefficient mathematical model of phenol extraction is established, which is based on a liquid-liquid extraction model and verified for accuracy by the experiment. The effect experiment result shows that with an increase in concentration of TBP and decrease in temperature, the extraction distribution coefficient increases and further determines the complex structures and the enthalpy change of the reaction. Meanwhile, a comparison of experimental and calculated values in the model experiment result shows that the average relative error of extraction distribution coefficient is $5.56 \%$ in different concentrations of TBP and $2.72 \%$ in different temperatures. Considering the error of the experiment, this work concludes that the distribution coefficient mathematical model of phenol extraction has a high predictive effect on the distribution coefficient and extraction rate of volatile phenol in actual wastewater.
\end{abstract}

Keywords: complex mechanism, phenol, TBP, distribution coefficient, mathematical model

\section{Introduction}

Coal gasification wastewater is a notorious toxic industrial effluent that urgently needs treatment because of its high concentration of pollution components, such as phenols, ammonia, carbon dioxide, hydrogen sulfide, and tar [1-2]. Phenols are considered priority pollutants [3] and have strong biological toxicity but

*e-mail: 13828830095@139.com

have high value as an important chemical raw material [4]. These pollutants are difficult to biologically degrade because of their toxicity and high concentration [5-7]. A considerably high concentration of phenols in water [8-9] is generated and discharged into the environment without effective treatment of wastewater, causing a significant effect on the ecosystem. Therefore, a pretreatment for removing phenols from wastewater is required to relieve the biological treatment burden and improve the recovery rate of phenols.

The physical extraction method, which is based on the solubility of phenol in different solvents, is the 
Table 1 . Basic water quality of wastewater.

\begin{tabular}{|c|c|c|c|c|c|c|}
\hline Water quality & Volatile phenol & $\begin{array}{c}\text { Nonvolatile } \\
\text { phenol }\end{array}$ & Total phenol & BOD & COD & Ammonia \\
\hline Content (ppm) & 4100 & 1063 & 5163 & 2810 & 16200 & 142 \\
\hline
\end{tabular}

main phenol extraction method [10]. At present, most gasification plants at home and abroad remove phenols from wastewater by physical extraction [11], such as at Harbin [12], Henan Yima [13], and United States Great Plains Gasification Plants [14], etc. However, this method has many problems [15-16], such as low extraction rate, significant solvent loss, and secondary pollution, which increase the biological treatment burden. In comparison with the physical extraction method, the complex extraction method [17-18], which is based on chemical reaction, is highly efficient and selective [19-21] in removing phenols. However, there has been little researches about it, especially its complex extraction mechanism.

Considering the extraction effect and economic cost, this work uses TBP [22-24] as the complexing solvent and kerosene as the diluent to investigate the mechanism of extracting phenol from coal gasification wastewater. First we analyzed the basic water quality of the wastewater. Then we researched the variety of main organic compounds in the wastewater by GC-MS and the complex mechanism of the extraction by IR. Meanwhile, we designed the effect experiment of the concentration of TBP and temperatures on distribution coefficient. Finally we validated the distribution coefficient model and compared the experimental and calculated values of distribution coefficients.

\section{Materials and Methods}

Materials

TBP, phenol, sulfuric acid, 4-aminoantipyrine, sodium thiosulfate, potassium iodide, bromine standard solution, kerosene
Ultraviolet spectrophotometer, infrared light metering instrument, Gas chromatography-mass spectrometry (GC-MS) (Agilent Technologies 7890A), ultrapure water meter, $\mathrm{pH}$ meter (Thermo Scientific Orion 4-Star, USA)

\section{Experimental Methods}

Equal volumes of the extraction solvent and the water sample were added into the liquid separating funnel and fully agitated for $10 \mathrm{~min}$ at constant temperature. Then they were statically separated (60 min). Finally, we obtained the equilibrium water phase and selected three samples to detect phenol content.

The concentration of volatile phenols was detected by 4-aminoantipyrine spectrophotometric analysis before and after extraction. The minimum detectable concentration of the analysis method was $0.1 \mathrm{mg} / \mathrm{L}$. The concentration of phenols in the equilibrium extraction phase was determined in accordance with the material balance calculation. The extraction distribution coefficient D is expressed in Equation (1).

$$
\mathrm{D}=\frac{\mathrm{Ce}}{\mathrm{Cw}}
$$

...where $\mathrm{Ce}$ and $\mathrm{Cw}$ denote the concentrations of the extraction and water phases, respectively.

\section{Results and Discussion}

\section{Water Quality Analysis}

The water sample consists of wastewater after removing ammonia from the Henan Yima Gasification

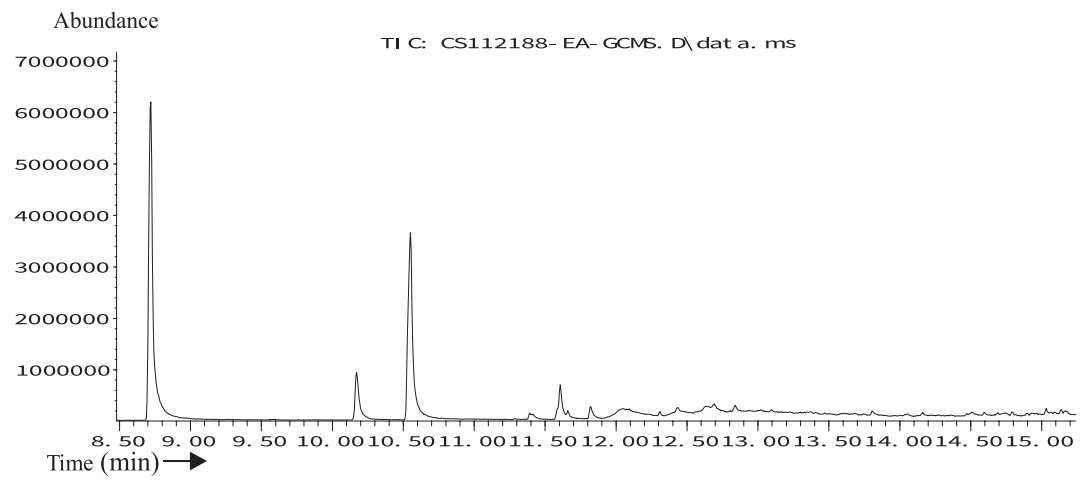

Fig. 1. Analysis of main organic compounds by GC-MS. 
Table 2. Variety of main organic compounds in wastewater.

\begin{tabular}{|c|c|c|c|c|c|}
\hline Number & Retention time/min & Component & Number & Retention time/min & Component \\
\hline 1 & 8.721 & Phenol & 8 & 12.050 & $\begin{array}{c}\text { 2-Hydroxy-6- } \\
\text { methoxyacetophenone }\end{array}$ \\
\hline 2 & 10.172 & 2-Methylphenol & 9 & 12.310 & 2-Ethyl-4-methylphenol \\
\hline 3 & 10.550 & 3-Methylphenol & 10 & 12.434 & $\begin{array}{c}\text { 2,6-Bis(hydroxymethyl)- } \\
\text { p-cresol }\end{array}$ \\
\hline 4 & 11.389 & 2,5-Dimethylphenol & 11 & 12.629 & $\begin{array}{c}\text { 6-Hydroxy-4- methyl group-2,3-two } \\
\text { methyl benzene }\end{array}$ \\
\hline 5 & 11.590 & 4-Ethylphenol & 12 & 12.694 & 5-Hydroxyhydrindene \\
\hline 6 & 11.606 & 2,3-Dimethylphenol & 13 & 12.840 & 4-Allylphenol \\
\hline 7 & 11.817 & 3,4-Dimethylphenol & 14 & 13.809 & 2-Naphthol \\
\hline
\end{tabular}

Plant. Table 1 shows the analysis result of the basic water quality of the wastewater.

Table 1 shows that the contents of total phenol, volatile phenol, and nonvolatile phenol reach 5163, 4100, and $1063 \mathrm{ppm}$, respectively. These values meet the characteristic of high phenolic content of gasification wastewater. Therefore, the treatment of phenols is necessary. Biodegradability (BOD/COD) is 0.17 , which is less than 0.3 (when biodegradability is more than 0.3 , the requirement of biological treatment is met). The water sample is the wastewater after removing ammonia; thus, the content of ammonia is reduced to $142 \mathrm{ppm}$.

Gas chromatography-mass spectrometry (GC-MS) is used to analyze the variety of main organic compounds in the wastewater [25]. Fig. 1 shows the result.

In combination with GC-MS spectrum data, the variety of the main organic compounds in the wastewater is shown in Table 2.

Fig. 1 and Table 2 show that the main organic compounds are phenols, benzene, and alcohol. Phenols are the most prevalent organic compound, and its variety is complex.

To further investigate the variety and content of phenols in the wastewater, an Agilent Technologies 7890A GC is used as a gas chromatograph, a DB-Petro capillary column is used as a chromatographic column, and a flame ionization detector is used as a detector. The external standard method is used for analysis [26]. Fig. 2 shows the analysis result.

In combination with $\mathrm{GC}$ spectrum data, the variety and content of phenols are shown in Table 3.

Fig. 2 and Table 3 show that the proportions of identified and unidentified phenols are up to $61.55 \%$ and $38.55 \%$, respectively.

\section{Effect of TBP Concentration on Extraction Distribution Coefficient D}

The concentration of TBP is the main factor in the extraction process [27]. With an increase in the concentration of TBP, the extraction distribution

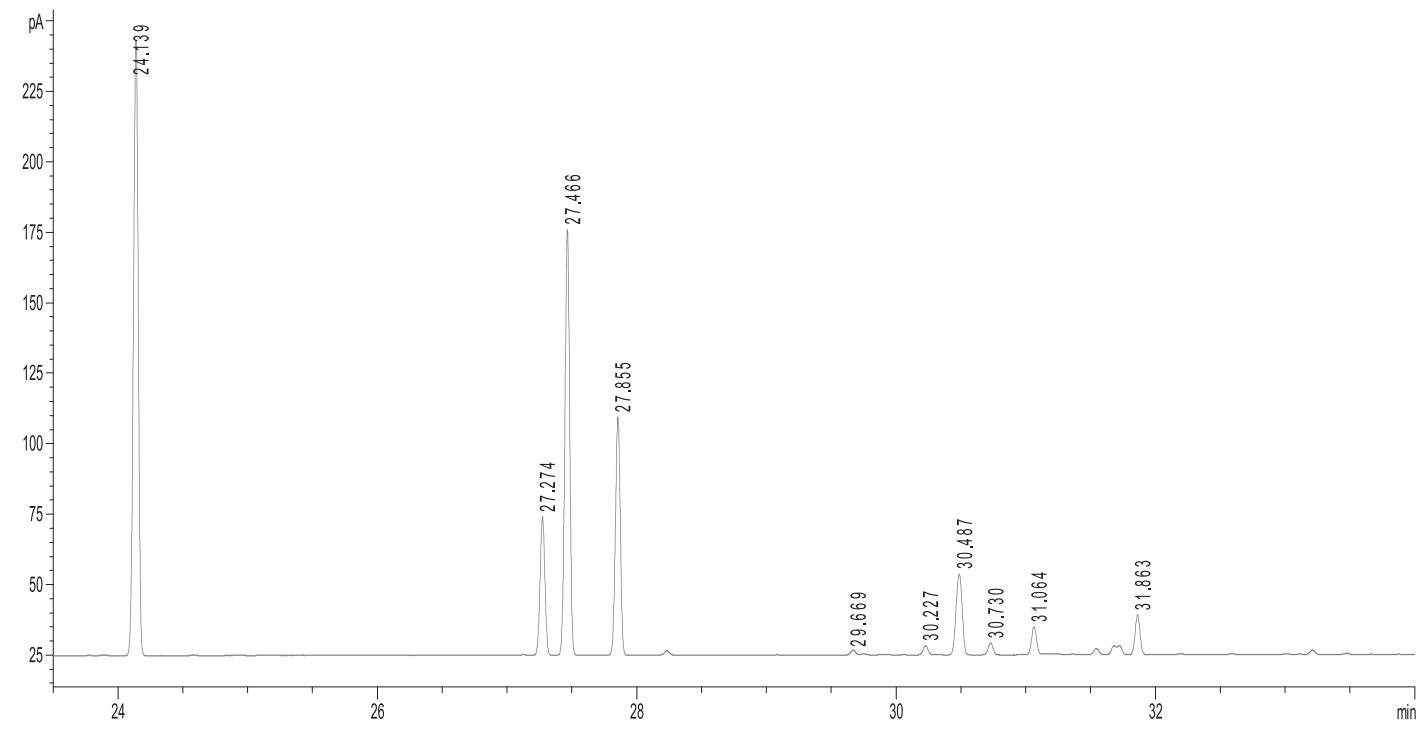

Fig. 2. Analysis of phenols by GC. 
Table 3. Variety and content of phenols.

\begin{tabular}{|c|c|c|c|c|c|}
\hline Number & Component & Proportion/\% & Number & Component & Proportion/\% \\
\hline 1 & Phenol & 21.39 & 9 & p-Ethylphenol & 0.89 \\
\hline 2 & o-Cresol & 4.85 & 10 & 2,6 -Dimethylphenol & 1.97 \\
\hline 3 & m-Cresol & 15.33 & 11 & 2,3 -Dimethylphenol & 0.33 \\
\hline 4 & p-Cresol & 8.52 & 12 & $3,4-$-Dimethylphenol & 1.44 \\
\hline 5 & o-Ethylphenol & 1.87 & 13 & 2-Naphthol & 0.76 \\
\hline 6 & 2,5 -Dimethylphenol & 0.77 & & Identified phenols & 61.45 \\
\hline 7 & m-Ethylphenol & 2.75 & \multicolumn{2}{|c|}{ Unidentified phenols } & 38.55 \\
\hline 8 & 2,4-Dimethylphenol & 0.58 & \multicolumn{5}{|c|}{ Total } \\
\hline
\end{tabular}

coefficient increases, leading to the consumption of a large amount of extraction solvent. To obtain the high extraction distribution coefficient and to reduce the consumption of extraction solvent, the effect of concentration on the extraction distribution coefficient must be investigated. To accurately analyze the effect of concentration on removing phenols, simulated water with a phenol content of $4100 \mathrm{ppm}$ (the content of volatile phenol in the wastewater is $4100 \mathrm{ppm}$.) is used to investigate the change of distribution coefficient with TBP concentration $\left(25^{\circ} \mathrm{C}\right)$. Fig 3 presents the results.

Fig. 3 shows that with an increase in concentration, the distribution coefficient increases significantly. When the concentration of TBP is 0 , the distribution coefficient is merely 1.94 . When the concentration of TBP increases to $10 \%$, the distribution coefficient significantly increases to 17.6. When the concentration of TBP is up to $50 \%$, the distribution coefficient reaches a maximum of 61.4 . However, $30 \% \mathrm{TBP}-$ kerosene is the best extraction solvent when the extraction effect and solvent consumption are considered.

To investigate the association mechanism of complex reaction, FT-IR is used to analyze the wave number change of the characteristic functional groups in the extraction phase [28]. Fig. 4 presents the graph.

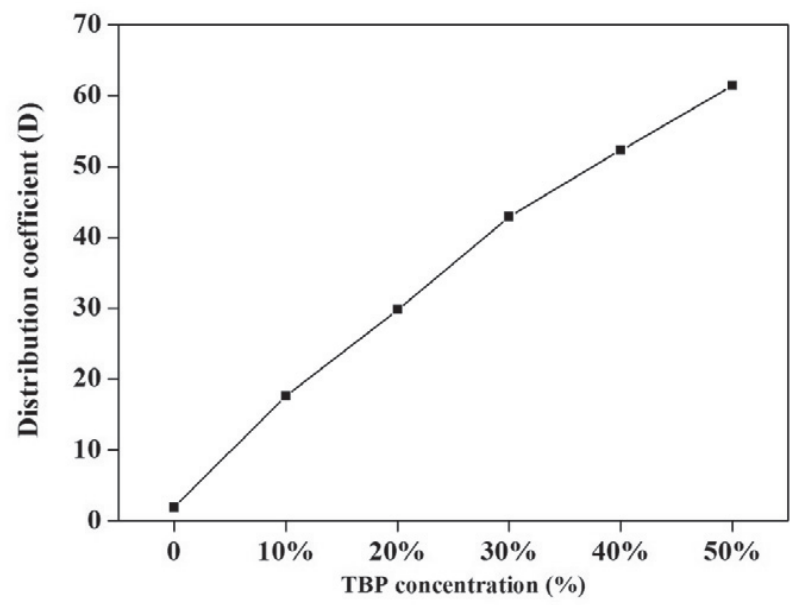

Fig. 3. Effect of concentration of TBP on distribution coefficient.
Fig. 4 shows that when TBP is loaded with phenols, a large wave number shift occurs on the characteristic peak of the $\mathrm{P}=\mathrm{O}$ bond of TBP. The wave number of the $\mathrm{P}=\mathrm{O}$ characteristic peak changes from $1272 \mathrm{~cm}^{-1}$ to $1239 \mathrm{~cm}^{-1}$. The wave number of the hydroxyl characteristic peak of phenol shifts from $3352 \mathrm{~cm}^{-1}$ to $3258 \mathrm{~cm}^{-1}$. However, the wave number of the methyl and methylene peak in TBP, which is in the range of $2870 \mathrm{~cm}^{-1}$ to $2960 \mathrm{~cm}^{-1}$, shows nearly no change. According to the wave number change of the characteristic functional groups, the association method of TBP and phenol is hydrogen bonding.

To further investigate the structure and composition of the complex formed by the complex reaction between TBP and phenol, the complexation ratio is assumed to be $1: n$. ArOH is used to represent phenol. The complex extraction equation is expressed in Equation (2).

$$
\operatorname{ArOH}+\operatorname{nTBP}(0) \stackrel{\mathrm{K}}{\Leftrightarrow} \operatorname{ArOH} \cdot \operatorname{nTBP}(\mathrm{o})
$$

The extraction equilibrium constant $\mathrm{K}$ is presented in Equation (3).

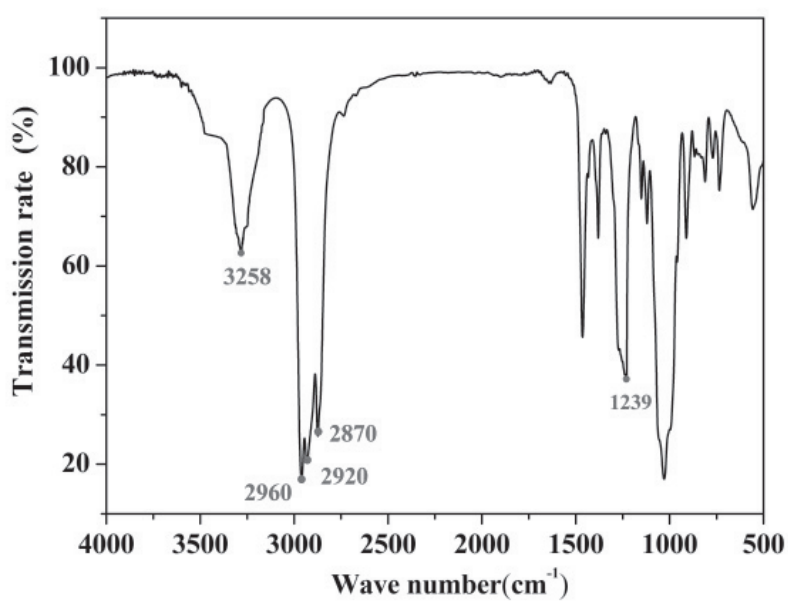

Fig. 4. IR spectra of TBP and phenol extracts. 


$$
\mathrm{K}=\frac{[\operatorname{ArOH} \cdot \mathrm{nTBP}(\mathrm{o})]}{[\operatorname{ArOH}][\mathrm{TBP}(\mathrm{o})]^{\mathrm{n}}}
$$

...where $[\mathrm{ArOH} \cdot \mathrm{nTBP}](\mathrm{o})$ is the concentration of the complex and [TBP](o) represents the concentration of TBP after extraction equilibrium.

The dissociation equilibrium equation of phenol is expressed in Equation (4):

$$
\mathrm{ArOH} \stackrel{\mathrm{K}_{\mathrm{a}}}{\Leftrightarrow} \mathrm{H}^{+}+\mathrm{ArO}^{-}
$$

The dissociation equilibrium constant $\mathrm{Ka}$ is presented in Equation (5):

$$
\mathrm{Ka}=\frac{\left[\mathrm{H}^{+}\right]\left[\mathrm{ArO}^{-}\right]}{[\mathrm{ArOH}]}
$$

...where $[\mathrm{ArOH}]$ is the concentration of phenol and [ArO-] denotes the concentration of negative ions in the water after the dissociation of phenol.

By combining Equations (2) and (4), the extraction distribution coefficient of phenol by complex extraction is expressed in Equation (6):

$$
\begin{gathered}
\mathrm{D}=\frac{[\mathrm{ArOH} \cdot \mathrm{nTBP}]}{[\mathrm{ArOH}]+\left[\mathrm{ArO}^{-}\right]}=\frac{[\mathrm{ArOH} \cdot \mathrm{nTBP}]}{[\mathrm{ArOH}]\left(1+\frac{[\mathrm{ArO}-]}{[\mathrm{ArOH}]}\right]}=\frac{[\mathrm{ArOH} \cdot \mathrm{nTBP}]}{[\mathrm{ArOH}]\left(1+10^{\mathrm{pH}-\mathrm{pKa}}\right)} \\
=\frac{\mathrm{K}[\mathrm{TBP}]^{\mathrm{n}}}{1+10^{\mathrm{pH}-\mathrm{pKa}}}
\end{gathered}
$$

By converting Equation (6) into a logarithmic equation, we can obtain Equation (7):

$$
\lg \mathrm{D}=\mathrm{n} \lg [\mathrm{TBP}](\mathrm{o})+\text { constant }
$$

In accordance with the relationship between $\operatorname{lgD}$ and $\lg [\mathrm{TBP}](\mathrm{o})$ in Equation (7), the equilibrium distribution coefficient $\mathrm{D}$ is determined in different concentrations of TBP and the equilibrium concentration of TBP is measured after extraction equilibrium. Table 4 shows the result.

The relationship of $\operatorname{lgD}$ and $\lg [\mathrm{TBP}]$ is formulated on the basis of the data in Table 4. Fig. 5 presents the results.

Table 4. Distribution coefficient of phenol in different concentrations of TBP.

\begin{tabular}{|c|c|c|c|}
\hline $\begin{array}{c}\text { Volume } \\
\text { fraction of } \\
\mathrm{TBP} / \%\end{array}$ & $\begin{array}{c}\text { Volume fraction } \\
\text { of kerosene/\% }\end{array}$ & $\begin{array}{c}\text { Concentration } \\
\text { of } \\
\mathrm{TBP} / \mathrm{mol} / \mathrm{L}\end{array}$ & $\mathrm{D}$ \\
\hline 10 & 90 & 0.3657 & 17.6 \\
\hline 20 & 80 & 0.7314 & 29.8 \\
\hline 30 & 70 & 1.0970 & 42.9 \\
\hline 40 & 60 & 1.4627 & 52.3 \\
\hline 50 & 50 & 1.8284 & 61.4 \\
\hline
\end{tabular}

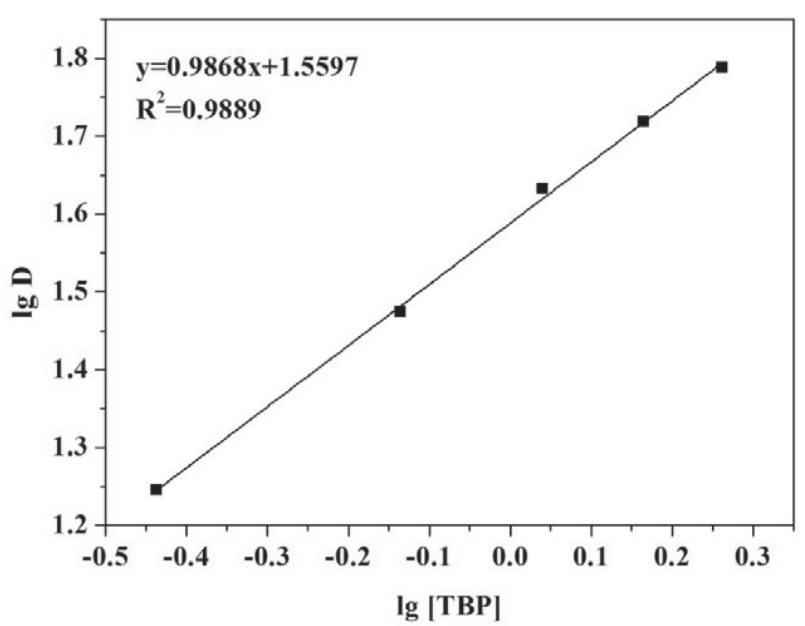

Fig. 5 Relationship of $\operatorname{lgD}$ and $\lg [\mathrm{TBP}]$.

Fig. 5 shows that the linear slope is 0.9868 , which is close to 1 . Thus, the complexation ratio of the complex composed of TBP and phenol is 1:1.

By combining the association mechanism of the complex reaction and the complexation ratio of the complex, the complex structure of TBP and phenol is determined.

The complex structure is as follows:

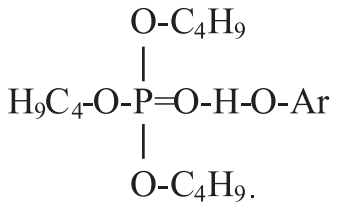

The complex extraction process is as follows:<smiles>CCO[Pb](OCC)(OCC)O[Ga]O[Mg]</smiles>

\section{Effect of Temperature on Extraction Distribution Coefficient D}

The temperature is the main factor affecting the extraction process [29]. When the temperature rises, it not only leads to a great loss of energy, but also to the reduction of distribution coefficient. To obtain a high extraction distribution coefficient and reduce the loss of energy, the effect of temperature on the extraction distribution coefficient must be investigated. Moreover, the content of volatile phenol in the wastewater is $4100 \mathrm{mg} / \mathrm{L}$. Therefore, to accurately analyze the effect of temperature on the extraction of phenol, we select a simulated water sample with a phenolic content of $4100 \mathrm{mg} / \mathrm{L}$ to investigate the effect of temperature on the extraction distribution coefficient. Fig. 6 presents the results.

Fig. 6 shows that temperature has a significant influence on the distribution coefficient. When the temperature is $20^{\circ} \mathrm{C}$, the distribution coefficient 


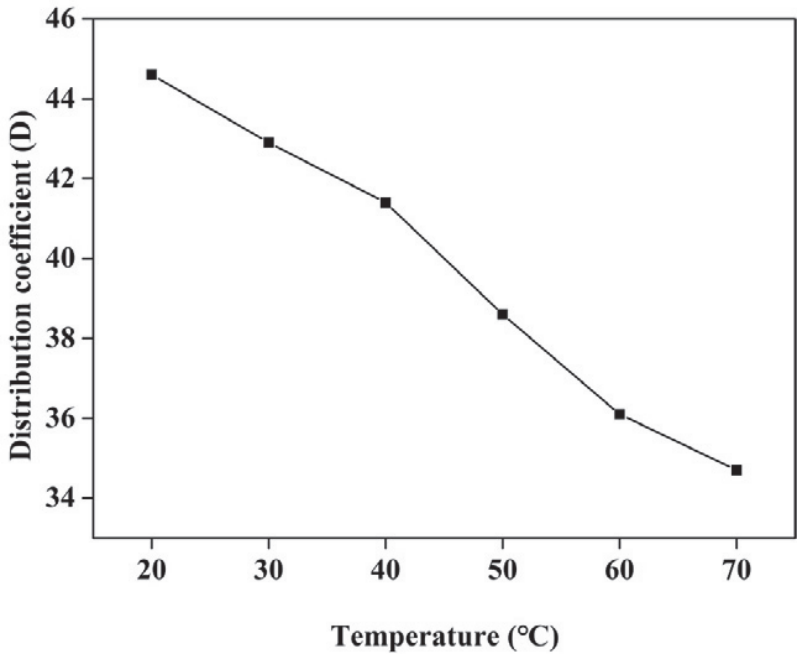

Fig. 6. Effect of temperature on distribution coefficient.

reaches the maximum of 44.6. While the temperature is increased to $70^{\circ} \mathrm{C}$, the distribution coefficient decreases to 34.7. With an increase in temperature, the distribution coefficient significantly decreases. Considering the extraction effect and loss of energy, we select $20^{\circ} \mathrm{C}$ as the best experiment temperature.

The enthalpy change $(\Delta \mathrm{H})$ of the complex reaction of TBP with phenol can be obtained in terms of the relationship curve between $\operatorname{lgK}$ and $1 / \mathrm{T}$ by introducing the Van't Hoff equation:

$$
\lg \mathrm{K}=-\frac{\Delta \mathrm{H}}{\mathrm{RT}}+C
$$

By integrating Equation (8), we can obtain Equation (9):

$$
\mathrm{K}=\exp \left(-\frac{\Delta \mathrm{H}}{\mathrm{RT}}+\mathrm{C}\right)
$$

In addition, due to the same extraction conditions, distribution coefficient (D) and equilibrium constant (K) satisfy the linear relationship. Hence, we can obtain Equation (10):

$$
\lg \mathrm{D}=-\frac{\Delta \mathrm{H}}{\mathrm{RT}}+\mathrm{C}
$$

Table 5. Distribution coefficient of phenol in different temperatures.

\begin{tabular}{|c|c|c|}
\hline Extraction solvent & Temperature $/{ }^{\circ} \mathrm{C}$ & $\mathrm{D}$ \\
\hline \multirow{3}{*}{$30 \%$ TBP-kerosene } & 30 & 42.9 \\
\cline { 2 - 3 } & 40 & 41.4 \\
\cline { 2 - 3 } & 50 & 38.6 \\
\cline { 2 - 3 } & 60 & 36.1 \\
\cline { 2 - 3 } & 70 & 34.7 \\
\hline
\end{tabular}

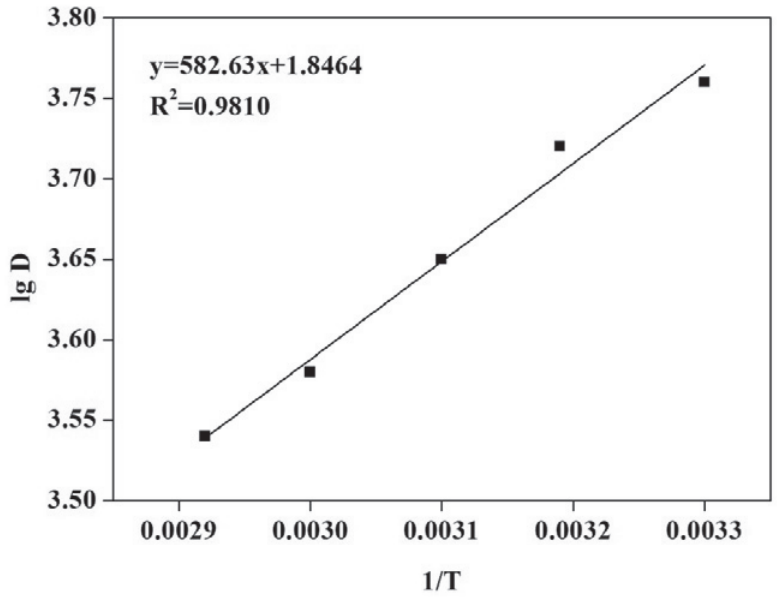

Fig. 7. Relationship of $\operatorname{lgD}$ and $\Delta \mathrm{H}$.

In accordance with the relationship between $\operatorname{lgD}$ and $\Delta \mathrm{H}$ in Equation (10), the extraction distribution coefficient is determined at $30^{\circ} \mathrm{C}$ to $70^{\circ} \mathrm{C}$ with $30 \%$ TBP-kerosene as the extraction solvent. Table 5 presents the result.

The relationship of $\lg \mathrm{D}$ and $\Delta \mathrm{H}$ is formulated on the basis of the data in Table 5. Fig. 7 presents the results.

Fig. 7 shows that the linear slope is 582.63. Therefore, the enthalpy change is $-4843.98 \mathrm{~J} / \mathrm{mol}$. The complex reaction of TBP with phenol is an exothermic reaction, and heating is not conducive to the extraction of the reaction.

\section{Complex Extraction Equilibrium Model of Phenol}

\section{Description of Complex Extraction Equilibrium}

To establish the extraction equilibrium model, the assumptions need to be formulated on the basis of the law of conservation of mass:

The activity of phenol in water and complex is proportional to its concentration.

The concentration of TBP is greater than that of phenol in water.

The total distribution coefficient is the sum of the distribution coefficients of the complex and physical extractions when the effect of kerosene on the physical extraction of phenol is considered.

\section{Establishing the Distribution Coefficient Model}

In addition to the complex equilibrium extraction and the dissociation equilibrium of phenol, the effect of kerosene on the physical extraction of phenol is also considered. The physical extraction of phenol is expressed in Equation (11).

$$
\operatorname{ArOH}(\mathrm{w}) \stackrel{m}{\Leftrightarrow} \operatorname{ArOH}(\mathrm{o})
$$


...where $[\mathrm{ArOH}](\mathrm{o})$ represents the concentration of phenol in the extraction phase after extraction, and $[\mathrm{ArOH}](\mathrm{w})$ is the concentration of phenol in the water phase after extraction. Thus, the physical distribution coefficient (m) is expressed in Equation (12):

$$
\mathrm{m}=\frac{[\mathrm{ArOH}]_{(\mathrm{o})}}{[\mathrm{ArOH}]_{(\mathrm{w})}}
$$

The total distribution coefficient (D(total)) is expressed in Equation (13):

$$
\mathrm{D}(\text { total })=\frac{[\mathrm{ArOH} \cdot \mathrm{nTOA}]+\varphi[\mathrm{ArOH}](\mathrm{o})}{[\mathrm{ArOH}]+\left[\mathrm{ArO}^{-}\right]}
$$

...where $\varphi$ represents the volume fraction of kerosene. By combining Equations (7), (9), and (10), we can obtain Equation (14):

$$
\mathrm{D}(\text { total })=\frac{\mathrm{K}[\mathrm{TBP}]^{\mathrm{n}}+\varphi \mathrm{m}}{1+10^{\mathrm{pH}-\mathrm{pKa}}}
$$

Equation (15) is derived by combining Equations (9) and (14)

$$
\mathrm{D}(\text { total })=\frac{\exp \left(-\frac{\Delta \mathrm{H}}{\mathrm{RT}}+\mathrm{C}\right)[\mathrm{TBP}]^{\mathrm{n}}+\varphi \mathrm{m}}{1+10^{\mathrm{pH}-\mathrm{pKa}}}
$$

In accordance with one hydroxyl of phenol, the negative logarithm (Pka) of the dissociation constant of phenol is 9.98. In accordance with the complexation ratio of the complex, $\mathrm{n}$ of the equation is 1 . In accordance with the relationship between $\operatorname{lgD}$ and $\Delta \mathrm{H}, \Delta \mathrm{H}$ of the reaction is $-4843.98 \mathrm{~J} / \mathrm{mol}$, and $\mathrm{n}$ of the equation is 1.8464. When the volume fraction of kerosene is $100 \%$, the distribution coefficient $(\mathrm{m})$ is 1.94 . Therefore, we can derive Equation (16):

$\mathrm{D}($ total $)=\frac{\left(\exp \left(-\frac{-4843.98}{\mathrm{RT}}+1.8464\right)\right)[\mathrm{TBP}]+1.94 \varphi}{1+10^{\mathrm{pH}-9.98}}$

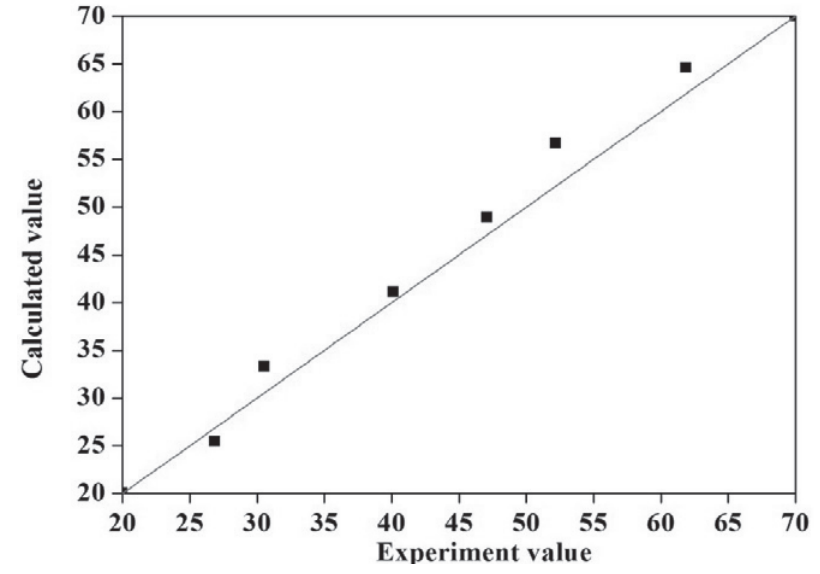

Fig. 8. Relationship of experimental and calculated values of distribution coefficient in different concentrations of TBP.

Equation (16) expresses the distribution coefficient model of extracting phenol.

\section{Validating the Distribution Coefficient Model}

To ensure the accuracy of the distribution coefficient model, the calculation value of the model needs to be validated by the experimental value of the distribution coefficient, which is extracted from the actual wastewater. Two variables of TBP concentration and temperature exist in the model; thus the model is validated from two sides.

First, the model is validated in different concentrations of TBP. The experimental condition is that the solvent water ratio is $1: 1$ at $23^{\circ} \mathrm{C}$ and singlestage cross-flow extraction. Moreover, the experimental values of the volatile phenol in the wastewater are collectively called phenols because of the complex types of phenol in the wastewater. Table 6 shows the result.

The relationship of the experimental and calculated values of the distribution coefficient is formulated on the basis of the data in Table 6. Fig. 8 presents the results.

Table 6 and Fig. 8 show that the average relative error of the experimental and calculated values of the distribution coefficient is $5.56 \%$ in different

Table 6. Comparison of experimental and calculated values of distribution coefficient in different concentrations of TBP.

\begin{tabular}{|c|c|c|c|c|c|c|c|}
\hline $\begin{array}{c}\text { Volume fraction } \\
\text { of TBP } \\
(\%)\end{array}$ & $\begin{array}{c}\text { Concentration } \\
\text { of TBP (mol/L) }\end{array}$ & $\begin{array}{c}\text { Volume } \\
\text { fraction of } \\
\text { kerosene }(\%)\end{array}$ & $\begin{array}{c}\text { Extraction } \\
\text { rate } \\
(\%)\end{array}$ & $\begin{array}{c}\text { pH of } \\
\text { equilibrium } \\
\text { water phase }\end{array}$ & $\begin{array}{c}\text { D (experimental } \\
\text { value) }\end{array}$ & $\begin{array}{c}\text { D (calculated } \\
\text { value) }\end{array}$ & $\begin{array}{c}\text { Relative } \\
\text { error (\%) }\end{array}$ \\
\hline $15 \%$ & 0.5486 & 85 & 96.41 & 6.47 & 26.86 & 25.42 & 5.35 \\
\hline $20 \%$ & 0.7314 & 80 & 96.83 & 5.56 & 30.55 & 33.26 & 8.86 \\
\hline $25 \%$ & 0.9143 & 75 & 97.57 & 6.32 & 40.15 & 41.08 & 2.32 \\
\hline $30 \%$ & 1.097 & 70 & 97.92 & 5.98 & 47.08 & 48.91 & 3.88 \\
\hline $35 \%$ & 1.279 & 65 & 98.12 & 6.35 & 52.19 & 56.69 & 8.62 \\
\hline $40 \%$ & 1.463 & 60 & 98.41 & 6.12 & 61.89 & 64.57 & 4.34 \\
\hline
\end{tabular}


Table 7. Comparison of experimental and calculated values of distribution coefficient at different temperatures.

\begin{tabular}{|c|c|c|c|c|c|}
\hline $\begin{array}{c}\text { Temperature } \\
\left({ }^{\circ} \mathrm{C}\right)\end{array}$ & $\begin{array}{c}\text { Extraction rate } \\
(\%)\end{array}$ & $\begin{array}{c}\mathrm{pH} \text { of equilibrium water } \\
\text { phase }\end{array}$ & $\mathrm{D}$ (experimental value) & $\mathrm{D}$ (calculated value) & $\begin{array}{c}\text { Relative } \\
\text { error }(\%)\end{array}$ \\
\hline 10 & 98.18 & 6.47 & 53.95 & 55.82 & 3.46 \\
\hline 20 & 98.06 & 5.56 & 50.55 & 52.13 & 3.14 \\
\hline 30 & 97.92 & 6.32 & 47.08 & 48.90 & 3.87 \\
\hline 40 & 97.9 & 5.98 & 46.67 & 46.07 & 1.28 \\
\hline 50 & 97.79 & 6.35 & 44.37 & 43.56 & 1.82 \\
\hline 60 & 97.57 & 6.12 & 40.22 & 41.34 & 2.79 \\
\hline
\end{tabular}

concentrations of TBP. The model has a high prediction accuracy of the distribution coefficient, considering the error of the experimental process.

Second, the model is validated in different temperatures. The experimental condition is that the extraction solvent is $40 \%$ TBP-kerosene at a 1:1 solvent:water ratio and single-stage cross-flow extraction. The experimental values of the volatile phenol in the wastewater are collectively called phenols because of the complex types of phenol in the wastewater. Table 7 shows the results.

The relationship of the experimental and calculated values of the distribution coefficient is formulated on the basis of the data in Table 7. Fig. 9 presents the results.

Table 7 and Fig. 9 show that the average relative error of the experimental and calculated values of the distribution coefficient is $2.72 \%$ at different temperatures. The model has a high prediction accuracy of the distribution coefficient, considering the error of the experimental process.

The model is suitable for the prediction of the actual wastewater distribution coefficient and the extraction rate when the solvent water ratio is $1: 1$ and extraction

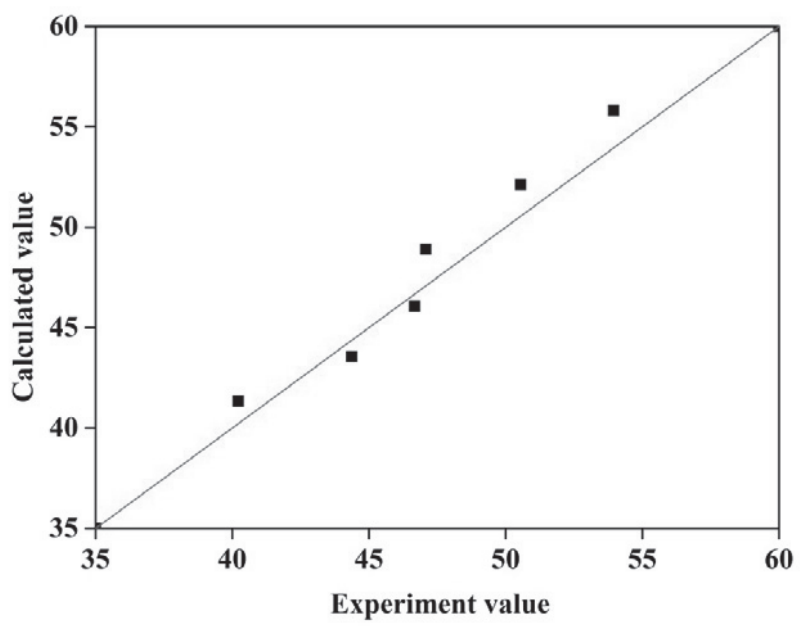

Fig. 9. Relationship of experimental and calculated values of distribution coefficient at different temperatures. is single-stage cross-flow, considering the error of the experimental process.

\section{Conclusions}

We investigated the complex mechanism of phenol extraction of coal gasification wastewater. The following conclusions were obtained by using TBP to remove phenol:

With an increase in TBP concentration, the distribution coefficient significantly increased. Considering the extraction effect and solvent consumption, we selected $30 \%$ TBP-kerosene as the best extraction solvent.

The association method of TBP and phenol was hydrogen bonding by FT-IR.

The complexation ratio of the complex composed of TBP and phenol was 1:1, as determined by the slope method. The complex structure and extraction process were further studied.

With an increase in temperature, the distribution coefficient significantly decreased. The complex reaction of TBP with phenol was exothermic, and the enthalpy change of the complex reaction of TBP with phenol was $-4843.98 \mathrm{~J} / \mathrm{mol}$.

The complex extraction equilibrium model of phenol was established considering that the total distribution coefficient was the sum of the distribution coefficients of the complex and physical extractions:

$$
\mathrm{D}(\text { total })=\frac{\left(\exp \left(-\frac{-4843.98}{\mathrm{RT}}+1.8464\right)\right)[\mathrm{TBP}]+1.94 \varphi}{1+10^{\mathrm{pH}-9.98}}
$$

By using the distribution coefficient model for validation, the average relative error of the experimental and calculated values of the distribution coefficient were $5.56 \%$ in different concentrations and $2.72 \%$ in different temperatures of TBP. With the error of the experimental process considered, the model was suitable for predicting the actual wastewater distribution coefficient and the extraction rate when the solvent water ratio was $1: 1$ and the extraction was single-stage cross-flow. 


\section{Acknowledgements}

Our research was supported by the National High Technology Research and Development Plan (No. 2015AA050501) and the National International Scientific and Technological Cooperation Project (No. 2015DFG61830).

\section{Conflict of Interest}

The authors declare no conflict of interest.

\section{References}

1. YU Z., CHEN Y., FENG D., QIAN Y.. Process Development, Simulation, and Industrial Implementation of a New Coal-Gasification Wastewater Treatment Installation for Phenol and Ammonia Removal. Ind \& Eng Chem Res, 49 (6), 2874, 2010.

2. KOHL A.I., NIELSEN R. Gas Purification, $5^{\text {th }}$ ed.; Gulf Publishing Company: Houston, TX, 1997.

3. WANG Z., XU X., GONG Z., YANG F. Removal of COD, phenols and ammonium from Lurgi coal gasification wastewater using A2O-MBR system. J Hazard Mater, 235-236 (20, 78, 2012.

4. MOHAMMADI S., KARGARI A., SANAEEPUR H., ABBASSIAN K., NAJAFI A., MOFARRAH E. Phenol Removal from Industrial Wastewaters: A Short Review. Desalin \& Water Treat, 46 (12), 2215, 2015.

5. DOUGLAS C., KING C.J. Solvent extraction of phenols from water. Ind Eng Chem Process Des, 21, 51, 1982.

6. WANG W., HAN H. Recovery strategies for tackling the impact of phenolic compounds in a UASB reactor treating coal gasification wastewater. Bioresource Technol, 103 (1), 95, 2012.

7. KHAKSAR A.M., NAZIF S., TAEBI A., SHAHGHASEMI E. Treatment of phenol in petrochemical wastewater considering turbidity factor by backlight cascade photocatalytic reactor. J Photoch Photobio A, 348, 2017.

8. LI H.Q., HAN H.J., DU M.A., WANG W. Inhibition and recovery of nitrification in treating real coal gasification wastewater with moving bed biofilm reactor. J Environ Sci-China, 23, 568, 2011.

9. LI H.Q., HAN H.J., DU M.A., WANG W. Removal of phenols, thiocyanate and ammonium from coal gasification wastewater using moving bed biofilm reactor[J]. Bioresource Technol, 102, 4667, 2011.

10. CHEN Y., WANG Z. Application research status of the chemical process of ammonia / phenol recovery from coalgasification wastewater. Coal Chem Ind, 41 (4), 44, 2013.

11. FU C.R., QU S.J., DONG W.G., GAO M.L., WANG J.K. Process simulation of extraction and removal of phenol from coal chemical wastewater. Clean Coal Technol, 23 (3), 94, 2017.

12. ZHOU Z.Y., TANG Z.G., CHEN C. Analysis and solution of phenolic water entrainment in the side output in the water tower of phenol recovery section. Coal Chem Ind, 32 (4), 47, 2004.
13. CHEN L., CHENG Y.F. Effect of $\mathrm{pH}$ value of wasterwater on phenol removal by extraction. Coal Chem Ind, 35 (4), 38, 2007.

14. MOOKETSI O.I. Evaluation of ozone for the removal of phenolic compounds in wastewater from the merisol plant (Sasolburg). Johannesburg: Degree of Masters of Science, University of Witwatersrand, 2009.

15. GAI H.J., JIANG Y.Y., QIAN Y. Analysis and debottlenecking retrofits for the coal-gasification wastewater treatment process. Chem Eng(China), 35 (8), 57, 2007.

16. QIAN Y., ZHOU Z.Y., CHEN Y. Process retrofit and industrial implementation of phenol and ammonia recovery from coal-gasification wastewater. Ciesc J, 6 (17), 1821, 2010.

17. KING C.J. Seperation process based upon reversible chemical complexation//Rousseau R W.E.d. Handbook of seperation process technology. New York: John Wiley\&Sons, 1987.

18. GU M.L, ZHAN J., LIU Y. Dephenolization using Complexation extraction method for treating waste alkaline liquor from an oil refinery. Environ Sci Technol, 29 (11), 31, 2006.

19. ZHANG H.X., CHENG Y.X. Progress of complexation extraction of carboxylic acid dilute solution. AnHui Chem Ind, 40 (2), 3, 2014.

20. ZHAO W.S., SUN Y., FENG W. The treatment of highly concentrated phenol-containing wastewater by complexation extraction. Shandong Chem Ind, 2015.

21. YANG D.L., NING P.G., CAO H.B. Extraction of phenol with primary amine N_(1923). Chinese J Process Eng, 12 (4), 570, 2012.

22. ZHANG L.J., FENG J.Z., YANG C.F., QIAN Y. Extraction-recover process of Phenols from Coalgasification Wastewater. Environ Chem, 25 (4), 488, 2006.

23. LIU C.Y., LIU L. Study on extraction by chemical complexation used in FCC caustic sludge acidification liquid. Pollut Control Technol, 22 (5), 5, 2009.

24. WU M.L. Determination of uranium in soil by ICP-OES after extracted by TBP. Shandong Chem Ind, 44 (14), 70, 2015.

25. WANG R.C., SUN M., LIU Q.X., MA Y.X., FENG G., XU L., MA X.X. Extraction and GC /MS analysis of phenolic compounds in low temperature coal tar from Northern Shaanxi. J China Coal Soc, 36 (4), 664, 2011.

26. RAVA E., CHIRWA E., ALLISON P., NIEKERK M.V., AUGUSTYN M.P. Removal of hard COD, nitrogenous compounds and phenols from a high-strength coal gasification wastewater stream. Water S A, 41 (4), 441, 2015.

27. YANG C., QIAN Y., ZHANG L., FENG J. Solvent extraction process development and on-site trial-plant for phenol removal from industrial coal-gasification wastewater. Chem Eng J, 117 (2), 179, 2006.

28. FU X.M., WANG L., DAI S.G. Mechanism Study on the Extraction of Nonylphenol by Ionic Liquids in Water Through IR Spectroscopy and Quantum Chemical Calculation. Spectrosc Spect Anal, 31 (3), 625, 2011.

29. LI D.Z. Analysis on the Factors Influencing Phenol Extraction in Coal Gasification Wastewater. Prog Qual PetroChina Chem Ind, 5, 15, 2013. 
